\title{
Memórias em torno de Apolônio de Tiana: feiticeiro, homem divino e rival de Jesus Cristo
}

\author{
Memories around Apollonius of Tiana: sorcerer, holy man and \\ rival of Jesus Christ
}

\author{
Semíramis Corsi Silva ${ }^{1}$
}

RESUMO

Objetiva-se, nesse artigo, mostrar como se constituíram duas memórias sobre o personagem de Apolônio de Tiana, uma como feiticeiro charlatão e outra como homem divino, no período do Principado romano. Para isso, apresentaremos como havia uma fronteira muito tênue entre práticas de cunho mágico não consideradas negativas, de outras tidas como maléficas dentro daquilo que os antigos gregos e romanos do Principado pensavam sobre a magia. Da mesma forma, buscaremos levantar aspectos sobre a construção de Apolônio de Tiana na documentação da Antiguidade Tardia e nos conflitos desse contexto. A partir disso, faremos considerações sobre as memórias em torno de Apolônio de Tiana na contemporaneidade, sendo que uma das memórias do personagem que a Antiguidade Tardia nos legou é sua constituição enquanto rival de Jesus Cristo.

Palavras-chave: Principado Romano. Memórias. Apolônio de Tiana. Magia. Jesus Cristo.

\section{ABSTRACT}

The article aims to show how two memories about Apollonius of Tyana were constituted, one as a sorcerer and charlatan and another as a holy man, in the Roman Principate. For this, we will present the very fine line that existed between what was considered beneficial and what was seen as a curse among what the ancient Greeks and Romans thought about the sorcery. Similarly, we will seek to show some

1 Doutora em História. Professora do Departamento de História e da Pós-graduação da Universidade Federal de Santa Maria(UFSM). Pesquisadora e Coordenadora do Grupo de Estudos sobre o Mundo Antigo Mediterrânico (GEMAM/UFSM) e do Grupo de Trabalho História Antiga da ANPUH/RS - GTHA-RS. e-mail: semiramiscorsi@yahoo.com.br 
aspects of the construction around Apollonius of Tyana in the documentation of the Late Antiquity and in the conflicts from that context. From this, we will address considerations about Apollonius of Tyana in the contemporary society, among which one of the memories of Apollonius the Late Antiquity left us is his constitution as a rival of Jesus Christ.

Keyword: Roman Principate. Memories. Apollonius of Tyana. Magic. Jesus Christ.

\section{Introdução}

Apolônio de Tiana foi um personagem que viveu, provavelmente, no século I d.C., estando sua realidade e possível trajetória permeadas por dúvidas. Nascido em Tiana, na província romana da Capadócia, causou admiração em algumas pessoas, como no sofista grego Flávio Filóstrato, que, em meados do século III d.C., lhe rendeu uma longa biografia apologética, a Vida de Apolônio de Tiana. ${ }^{2}$

Na VA, Filóstrato conta os feitos de Apolônio e, especialmente, destaca características de suas funções e relações com diferentes povos em suas viagens, que duraram toda a vida adulta do protagonista da obra. Além dessa obra de natureza biográfica escrita por Filóstrato, temos algumas referências a Apolônio na cultura material, menções sobre a personagem em textos anteriores e posteriores a Filóstrato e uma série de cartas transmitidas pela tradição manuscrita como de autoria de Apolônio. ${ }^{3}$

Além das representações do tianeu, epíteto do protagonista do texto, em documentos textuais antigos, Apolônio foi utilizado em práticas mágicas conforme testemunhos da cultura material, como nas relacionadas ao uso de talismãs - $\tau \lambda \lambda \dot{\varepsilon} \sigma \mu \alpha \tau \alpha$ - telesmata difundidos no século IV d.C., em que seu nome aparece gravado (CORNELLI, 2001, p.65), bem como em outros testemunhos materiais que apresentaremos.

Também sabemos da existência de um grupo de seguidores de Apolônio do contexto do Principado romano, os apolíneos (VA, VIII, 21), ${ }^{4}$ da construção de um templo para Apolônio pelo imperador Caracala (DIÃO CÁSSIO, História Romana, LXXVIII, 18, 4 e FILÓSTRATO, VA, VIII, 31), da possível admiração da dinastia dos Severos por Apolônio (VA, I, 3 e História

2 Abreviaremos o título da obra como VA conforme regras de abreviação do Oxford Classical Dictionary. 3 No entanto, a autoria das cartas é debatida por estudiosos como Robert Penella (1979), que acreditam que as mesmas possam não ser de fato de Apolônio.

4 Por Principado estamos nos referindo ao governo do princeps (imperador romano). Os historiadores utilizam o termo Principado para se referirem ao período correspondente aos primeiros séculos do Império Romano (séculos I, II e meados do século III d.C.). O período posterior é chamado por nós de Antiguidade Tardia, últimos séculos do Império Romano, contexto de grandes transformações nas estruturas sociais, econômicas, mentais e culturais que conduzirão ao período denominado de Idade Média na historiografia. 
Augusta, Vida de Severo Alexandre) e do envolvimento do nome de Apolônio de Tiana em polêmicas cristãs e anticristãs do século IV, que trataremos neste artigo.

Sabemos ainda que Apolônio chegou a ser admirado no século XVI, quando o renascentista Johannes Stradanus produziu uma série de desenhos sobre a narrativa de suas viagens feita por Filóstrato (YSSELT, 1994). Apolônio também é intensamente citado atualmente em sites de ocultismo, gnose e outras práticas mágico-religiosas, o que pode ser visto em uma simples busca pela internet.

$\mathrm{Na}$ documentação antiga propriamente, fragmentária como grande parte da documentação da Antiguidade que temos hoje, podemos ver que o tianeu foi um personagem muito polêmico e que a forma como seu nome aparece relacionado às práticas mágicas do Principado mostra-nos o interessante aspecto ambíguo que a sociedade grecoromana pré-cristã concedia à magia, ora considerada uma prática não perigosa e fonte de estudos filosóficos sistematizados, ora considerada uma prática charlatanesca que devia ser punida pelas leis. ${ }^{5}$

O objetivo deste artigo, portanto, é analisar as referências que temos sobre Apolônio de Tiana na obra de Filóstrato e nos demais testemunhos da Antiguidade, buscando apresentar como havia uma fronteira muito tênue entre o que era considerado benéfico e o que era tido como um malefício dentro daquilo que os antigos gregos e romanos do Principado pensavam sobre as práticas mágicas. A partir disso, visamos mostrar como se constituíram duas memórias sobre Apolônio de Tiana, uma como feiticeiro charlatão (um yóns - goes, praticante da magia considerada nefasta, a goeteia, nos termos usados na documentação) e

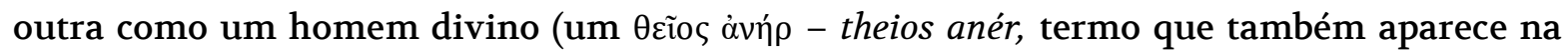
documentação) no Principado. ${ }^{6}$

Buscaremos também, ainda que brevemente, levantar alguns aspectos sobre a memória de Apolônio de Tiana na documentação da Antiguidade Tardia e como atualmente tais memórias são revisitadas. Portanto, não estamos buscando pelo Apolônio histórico em si, mas pelos "Apolônios" apresentados nos documentos que tivemos acesso.

Também cumpre ressaltar que estamos compreendendo por memória não memórias individuais propriamente, ainda que estejamos analisando textos e documentos de autores específicos, mas memórias coletivas, construídas historicamente sobre um personagem a partir de uma seleção de concepções reconhecidas culturalmente. Ou seja, memórias construídas através das escolhas, conscientes ou não, dos autores, em usar determinados

5 O uso da magia foi proibido em toda a tradição jurídica romana. Desde a Lei das Doze Tábuas, primeiro conjunto de leis romanas escritas, é possível acusar uma pessoa como responsável por práticas que podemos considerar relacionadas com o que os antigos romanos compreendiam como magia. Mais informações sobre o tema (RIVES, 2003).

6 Ao utilizarmos o termo feiticeiro estamos nos referindo ao yóns - goes, embora seja preciso destacar que o termo feiticeiro em si não existia no contexto trabalhado por nós. 
códigos históricos compartilhados no Principado romano, especialmente sobre as práticas mágicas. Tais escolhas, para nós, perpassaram pelos anseios e visões de mundo dos escritores e por jogos de poder, uma vez que consideramos, como aponta Jacques Le Goff (1990, p. 422), que a memória coletiva é parte das lutas sociais pelo poder e, acrescentamos, pelo ordenamento social. Tais memórias, há de se considerar, contribuíram para construir conhecimento e perpetuar imagens sobre o personagem de Apolônio até a contemporaneidade.

Após esta introdução, mostraremos, ainda que de maneira geral, concepções sobre a magia no período do Principado romano. Feito isso, ligaremos as construções de Apolônio a estas concepções e às tradições posteriores.

\section{A ambiguidade em relação à magia no Principado Romano e nas representações de Apolônio de Tiana}

Podemos considerar como magia fenômenos de diversas naturezas que têm em comum a ideia de, por meio de elaborados rituais e técnicas, agir sobre a realidade sensível. Temos diversos testemunhos sobre o que a sociedade greco-romana do Principado considerava magia, como textos escritos apresentando representações e muitos documentos da cultura material apresentando as práticas propriamente.

Práticas de magia amorosa, práticas de magia relacionadas a competições esportivas, a intrigas familiares, disputas comerciais, etc. são atestadas nos defixios, finas lâminas de

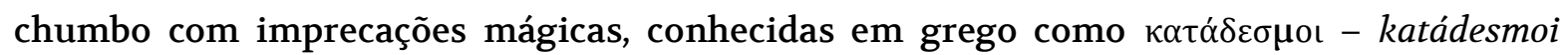
(RENBERG, 1997), depositadas em cemitérios, santuários, encruzilhadas, etc. Entretanto, centraremos nossa análise em textos escritos, onde encontramos mais informações sobre Apolônio.

Uma primeira realidade que os textos nos trazem, em nossa percepção, é a ambiguidade do que era a prática mágica na mentalidade dos escritores, membros dos grupos das elites do Império. De maneira geral, nessas representações havia uma distinção entre práticas de

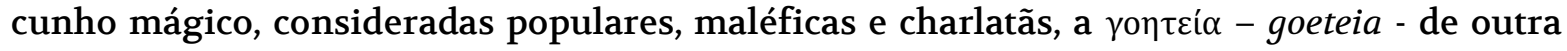
magia incorporada em rituais oficiais de deuses da religiosidade romana e parte de estudos

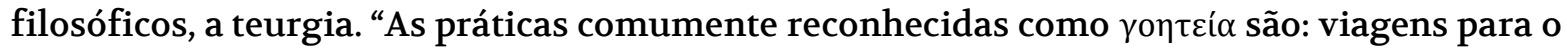
inferno, práticas mediúnicas, necromancia, simpatias, maldições, e todo tipo de persuasão oculta" (CORNELLI, 2001, p. 27). 
Já a teurgia, de acordo com Joseph Bidez (apud DODDS, 2002, p. 284), era um tipo de prática de magia baseada na relação entre espíritos celestes. O objetivo principal da teurgia era, assim, atingir as forças divinas, sendo oposta a goeteia, que invocaria forças maléficas, na crença dos antigos escritores. A teurgia, portanto, era uma assimilação de rituais religiosos e especulações filosóficas com uma base mágica. A fim de atingir o conhecimento, os filósofos teurgos praticavam ritos mágicos. Conforme Jacyntho Lins Brandão (1991, p. 113114), a magia ligada à filosofia, por um lado, era considerada um conhecimento místico, por outro, era uma espécie de conhecimento científico, o que fazia com que fosse aceita por largas faixas das camadas mais eruditas do Império Romano.

O termo $\mu \alpha \gamma \varepsilon i ́ \alpha$ - mageia, do qual deriva o vocábulo magia do português moderno, por sua vez, era usado para definir as práticas religiosas dos persas, que, no entanto, não foram sempre consideradas de maneira negativa na literatura. Etimologicamente a palavra "magia", mageia no grego e magia no latim, parece ter originado da raiz sânscrita mah, grande, significando a atividade do mago.

Havia ainda uma variedade de termos em latim e grego para identificar os praticantes do que podemos englobar como magia, tais como os termos: goes, vates, vaticinium, mathematicus, maleficus, hariolous, philosophus, mantis, chaldaeus. Pela quantidade de denominações, vemos que tais práticas eram consideradas um conhecimento também variado. E, como vimos, a concepção sobre esse conhecimento - maléfico ou não - tinha suas fronteiras também extremamente tênues e variáveis.

Podemos considerar que na sociedade greco-romana imperial havia diferentes termos que, entretanto, designavam uma única classe de fenômenos e os filósofos buscavam preponderar a característica religiosa de suas práticas, mas entre a teurgia e a goeteia, havia uma fronteira pouco demarcada.

Um exemplo de práticas teurgicas na Antiguidade é a ligação de muitos filósofos com os daimones. O daimon, ou gênio, eram o que os antigos gregos e romanos acreditavam como seres superiores capazes de intermediar a relação entre os homens e as divindades.

No século IV d.C., o historiador Amiano Marcelino, em suas Histórias $(21,14,5)$, ligou a fama de Apolônio de Tiana ao seu contato com estes gênios.

Igualmente nos é mostrado pelos imortais poemas de Homero que não são os deuses celestiais que se misturam ou ajudam os combatentes, mas sim espíritos familiares (gênios) que convivem com eles. Este foi o apoio, o que causou a eminência de Pitágoras, Sócrates, Numa Pompilio, o velho Cipião e (como alguns pensam), Mário, Otávio (que 
foi chamado de "Augusto", o grande), Hermes Trismegisto, Apolônio de Tiana e Plotino (AMIANO MARCELINO, Histórias, 21, 14, 5). ${ }^{7}$

Assim, Apolônio de Tiana pode ser considerado como um personagem paradigmático para a percepção da ambiguidade nas concepções sobre a magia no Principado. Em relação à cultura material, referências a Apolônio aparecem em uma inscrição honorífica de Mopsouhestia (atual Adana, na Turquia), com os seguintes dizeres: Este homem, nomeado assim por relação com Apolo, e brilhando de Tiana, extinguiu os erros da humanidade. O... de Tiana... mas no céu verdadeiro... ele afasta as tristezas dos mortais" (JONES, 2006, p. 131).

Também vemos referências a práticas de magia com o uso do nome de Apolônio de Tiana em um papiro mágico grego: "Uma velha mulher, a serva de Apolônio de Tiana. Tome o crânio de Tiphon e escreva os seguintes caracteres com o sangue de um cachorro negro [...]. Este feitiço foi testado" (JONES, 2006, p. 131).

Há menções, como já comentamos, de talismãs atribuídos a Apolônio em PseudoJustino, autor do século IV, e em outros autores da Antiguidade Tardia e da Idade Média. Os Pais da Igreja do período tardo-antigo criticaram duramente esses talismãs, mas pela eficácia que muitas pessoas acreditavam que eles possuíam, já que pensavam que Apolônio teria os criado por seus conhecimentos das forças da natureza e não por seu poder sobrenatural, os mesmos foram tolerados pela Igreja Medieval, sendo quase reconhecidos oficialmente, como nos informa Cornelli (2001, p. 65).

Ainda temos descrições feitas por cronistas bizantinos da existência de monumentos dedicados a Apolônio com poderes apotropaicos, erguidos em Bizâncio.

Na tradição de textos do Principado que chegaram até nossos dias, vemos Apolônio sendo mencionado de maneira negativa nos escritos de Luciano de Samósata, que diz: "Este mestre e amante era tianeu do círculo de Apolônio e dos que sabiam de toda a sua tragédia, já vês de que tipo é o homem de quem te falo" (LUCIANO, 1988, p. 5).

De acordo com o historiador Fernando Gascó (1986, p. 280), com quem concordamos, podemos também considerar a passagem XXIX da obra Philopseudes, de Luciano, como menção irônica e crítica a Apolônio: "Neste momento entrou na casa o pitagórico Arígnoto e o de cabelo comprido e aspecto solene. Já se sabe a quem me refiro, àquele que goza de tanta fama por sua sabedoria e que leva o nome de divino."

\footnotetext{
7 As citações antigas sobre Apolônio de Tiana deste texto, como essa, com exceção das contidas nas obras de Luciano, Filóstrato e Dião Cássio, estão na parte da obra editada por Christopher Jones como Testimonia. Este trabalho é um catálogo realizado por Jones que reúne e traduz para o inglês, no volume III da VA publicado pela Harvard University Press (Loeb Classical Library), uma série de menções a Apolônio de Tiana em grego e latim na documentação escrita e na cultura material. As traduções do inglês para o português são nossas.
} 
Aparecem menções a Apolônio também nos textos do historiador Dião Cássio, quando o autor se refere de maneira duvidosa à visão da morte do imperador Domiciano por Apolônio, também relatada na $V A$ (VIII, 26) por Filóstrato.

Certo Apolônio de Tiana, naquele mesmo dia e naquela mesma hora, quando Domiciano estava sendo assassinado (como que determinando precisamente os eventos que aconteciam em ambos os locais) subiu no alto de uma rocha em Éfeso (ou possivelmente em outro lugar) e, tendo reunido a população, proferiu estas palavras: "Bom, Stéfano! Bravo, Stéfano! Fere o desgraçado sanguinário! Atingiste, feriste, mataste." Isso é o que realmente aconteceu, embora eu duvide dez mil vezes (DIÃO CÁSSIO, História Romana, LXVII, 18).

Dião Cássio também deprecia as práticas religiosas do imperador Caracala (211-217) ligadas a Apolônio de Tiana.

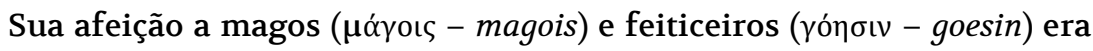
tão grande que ele elogiou e honrou a Apolônio da Capadócia, que viveu na época de Domiciano e foi julgado como mago e feiticeiro. A este ele ergueu um templo (DIÃO CÁSSIO, História Romana, LXXVIII, 18, 4).
}

Entretanto, como já mencionamos, o contemporâneo de Dião Cássio e do imperador Caracala, Filóstrato, desenvolve um longo relato sobre Apolônio de Tiana, apresentando o personagem de uma maneira totalmente diferente da imagem de feiticeiro charlatão mostrada em Luciano de Samósata e em Dião Cássio. Em Filóstrato, Apolônio de Tiana é considerado um homem sábio, cuja sabedoria transcende ao humano e, em razão disso, é um

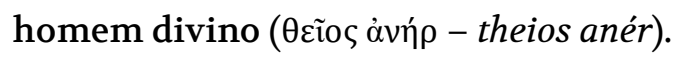

Embora no início da VA Filóstrato mostre que Apolônio teve relações com os magos ( $\mu$ ó үoıs - magois) da Babilônia, o biógrafo ressalta o caráter de sabedoria do biografado e seu estatuto enquanto homem divino, negando-lhe o título de mago - Filóstrato o chama de sábio - e também a ligação de filósofos como Empédocles, Pitágoras, Demócrito e Platão com este tipo de arte. 
A Apolônio, no entanto, ainda que se ocupasse de práticas semelhantes a estas e se aproximasse da sabedoria de maneira mais divina que Pitágoras por sua negação às tiranias, e apesar de ter nascido em tempos nem tão antigos, nem tão recentes, os homens ainda não o conhecem por sua sabedoria, que praticava de maneira filosófica e verdadeira. Mas, ao invés disso, alguns falam dele por uma coisa, outros por outra, outros ainda por ter relações com os magos da Babilônia, os brâmanes da Índia e os gimnosofistas do Egito, o consideram um mago ou o caluniam como um intruso entre os sábios, por lhe conhecerem mal. Porque Empédocles, o próprio Pitágoras e Demócrito, que conviveram com os magos e disseram muitas verdades sobrenaturais, nunca se sentiram atraídos por esta arte. E Platão, que foi ao Egito e que misturou muitas coisas de profetas e sacerdotes deste lugar com suas próprias teorias e que, como um pintor, deu cores ao que já tinha esquematizado, jamais foi tomado por um mago, mesmo quando lhe invejaram mais que nenhum outro por sua sabedoria.

Assim, tampouco o feito de ter pressentido e previsto muitas coisas poderia incluir Apolônio neste tipo de conhecimento [...] (VA, I, 2).

O caráter divino de Apolônio aparece na VA, quando Filóstrato ressalta seu biografado com tal característica por ser um sábio superior aos demais, sendo este elemento expresso pelo próprio autor/narrador ou pelas falas de diversos personagens da obra. Os poderes de Apolônio são descritos por Filóstrato como quando ele consegue ressuscitar uma jovem ( $V A$, IV, 45), sua capacidade de cura (VA, VI, 43), sua capacidade de livrar Éfeso de uma praga ( $V A$, IV, 10), seu poder de exorcismo ( $V A, \mathrm{IV}, 20)$, sua capacidade de descobrir um tesouro escondido (VA, VI, 39), quando ele livra sua perna das correntes que o prendiam (VA, VII, 38), desaparece em Roma e aparece em Dicearquia (VA, VII, 41), tem uma visão do momento exato da morte de Domiciano (VA, VIII, 26), desmascara uma empusa, espécie de vampiro, que se passava por uma linda mulher para seduzir e devorar o sangue e o corpo do filósofo Menipo (VA, IV, 25), entre outras passagens.

Já nas cartas tidas como de sua autoria, Apolônio aceita bem a ligação com a magia

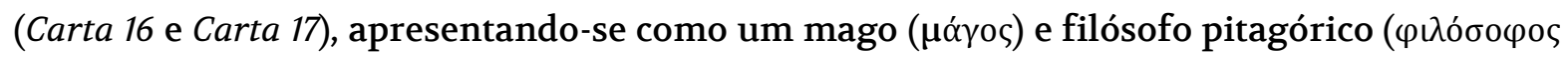

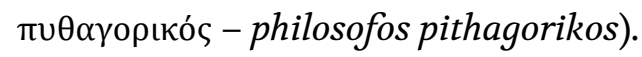

Para Eufrates: Julgas que devem ser chamados de filósofos os que seguem Pitágoras, e da mesma forma, sem dúvida, aqueles que seguem 
a Orfeu. Mas eu penso que mesmo aqueles que seguem a Zeus devem ser chamados magos, se pretendem ser piedosos e honrados (Carta 16).

Para Eufrates: Os persas chamam os homens piedosos de magos, de modo que aquele que adora os deuses ou tem uma natureza divina é um mago. Mas tu não és um mago, e sim um incrédulo (Carta 17).

No entanto, a magia na qual ele se apresenta ligado é a religiosidade dos persas, mostrando-nos que o termo mago era aceito neste sentido, já que para as práticas consideradas charlatãs havia outras expressões, como vimos. Desta forma, o que vemos é que Apolônio assume nas cartas sua ligação com a magia enquanto prática religiosa persa. Na $V A$ Filóstrato busca defender seu personagem do sentido negativo que a magia poderia ter em sua época de maneira clara nessa passagem.

Tomemos, no entanto, em consideração, outros argumentos: os feiticeiros (yóns - goes) - e eu os considero os mais infortunados dos homens - recorrem uns ao interrogatório de espíritos, outros a sacrifícios bárbaros, outros a pronunciar algum verso ou a untar-se com algo, afirmando que podem alterar o curso do destino. Muitos deles, submetidos a acusações, reconhecem ser expertos em tais procedimentos. Mas nosso homem se submetia aos ditados das Moiras e pressentia, como necessário, determinados acontecimentos, ele os conhecia de antemão, não por praticar a goeteia, e sim por revelação divina $(V A, \mathrm{~V}, 12)$.

Assim, o biógrafo não nega às práticas de cunho mágico do biografado, mas as imprime um caráter divino e defende o saber no qual Apolônio estava envolto. Mas, mesmo assim, ao relacionar Apolônio com os sábios magos persas, Filóstrato mostra certa ressalva, como vimos.

Em outra passagem da $V A$, por exemplo, pela capacidade de Apolônio em se libertar das correntes que o prendiam durante a prisão ordenada por Domiciano, ele é visto como alguém com capacidades sobre-humanas, mas nunca como um feiticeiro no sentido negativo que isso poderia ter naquele contexto, traduzindo goes aqui como feiticeiro. Filóstrato também se utiliza do relato sobre a libertação de Apolônio das correntes para desenvolver uma dura crítica à goeteia em oposição às capacidades miraculosas divinas de seu protagonista, o que é mostrado em $V A$, VII, 38. 
Filóstrato ainda comenta (VA, VIII, 31) que visitou um templo dedicado pelo imperador a Apolônio na cidade de Tiana, não mencionando quem é esse imperador, mas que, segundo Dião Cássio, em passagem já citada (História Romana, LXXVIII, 18, 4), foi Caracala. Ou seja, Apolônio chegou a ser admirado a ponto de ter um templo para sua reverência, apesar da imagem negativa ligada à nefasta goeteia que vemos em outros textos.

O momento que temos a maior defesa das práticas mágicas de Apolônio como teurgia em oposição à goeteia é na descrição da autodefesa de Apolônio por Filóstrato perante a acusação como praticante de magia feita pelo imperador Domiciano. Assim Apolônio, ou melhor, seu biógrafo, diz:

Quanto a essa arte, todos seus praticantes são gananciosos, pois as engenhosas demonstrações que fazem, as fazem para obter benefícios e gastam muito dinheiro enganando os que desejam alguma coisa, lhes convencendo de que são capazes de tudo. Desta forma, vê alguma riqueza em mim, imperador, para acreditar que me dedico a essa falsa sabedoria? Além disso, vosso pai me considerava acima do desejo de riqueza $(V A$, VIII, 7,3$)$.

Apolônio advoga em causa própria frente ao tribunal. A defesa de Apolônio, mostrada por Filóstrato, por sua vez, segue como uma defesa da filosofia, da mesma forma que no século II d.C. o escritor romano-africano Apuleio defendeu-se da mesma acusação, o que nos é mostrado na obra Apologia, a transcrição da autodefesa de Apuleio, como podemos ler nas passagens a seguir:

Confiado, sobretudo, neste principio, fico feliz por ter tido a sorte de ter a ampla possibilidade de defender a pureza da filosofia frente a ignorantes e provar minha inocência ante um juiz como tu (Apologia, I, 3).

Com efeito, assino a defesa não somente em minha própria causa, mas também em nome da filosofia, cuja majestade não admite a menor reprovação, como se tratasse da acusação mais terrível. E faço-o porque há pouco tempo os advogados de Emiliano [o acusador], com eloquência venal, disseram contra minha pessoa, particularmente, todas as invenções caluniosas que lhes ocorreram e, contra os filósofos 
em geral, todos demais tópicos que possam estar na boca dos ignorantes (Apologia, III, 6).

Assim como Apuleio, em vários trechos, como podemos ler, Apolônio mostra a Domiciano que, ao acusá-lo, o imperador se opõe à filosofia, citemos dois deles:

Na causa entre mim e o imperador, quem será o juiz? Prosseguiu Apolônio. Pois vou demonstrar que ele cometeu injustiça contra a filosofia (VA, VIII, 2).

Que grau de verdade alcança essa acusação fica evidente no testemunho destes senhores, pois eu não estava nos subúrbios, mas na cidade; não estava fora das muralhas, mas em uma casa; não estava com Nerva, mas com Filisco; não estava degolando, mas suplicando por uma vida; não estava em favor do império, mas da filosofia [...] (VA, VIII, $7,15)$.

Portanto, tanto Apuleio em sua defesa, quanto Filóstrato na defesa de Apolônio, usam a filosofia para legitimar as práticas de magia dentro dos limites que eram aceitos, rebatendo a acusação. Cumpre ressaltar que esta acusação de Apolônio apresentada por Filóstrato, não mencionada nas cartas tidas como do próprio tianeu, é considerada por alguns estudiosos, como Alberto Bernabé Pajares (1979, p. 465), como invenção filostratiana.

Acreditamos que seja possível que Filóstrato tenha criado essa acusação e também sua defesa, uma vez que isso lhe daria mais oportunidades para defender seu biografado das nefastas práticas da goeteia, especialmente diante da maior preocupação legal com a magia no período da dinastia dos Severos, quando Filóstrato escreveu a obra, com as Sentenças de Paulo. Com as Sentenças de Paulo, jurisconsulto contemporâneo a Caracala, as artes mágicas e divinatórias atraem uma atenção especial, e até mesmo a posse de livros mágicos (libri artis magicae), passa a ser proibida. Paulo determina que todos os culpados de praticarem magia, feiticeiros, adivinhos, astrólogos e seus consulentes, deveriam ser expostos às feras ou crucificados ou, ainda, queimados vivos. Também seriam punidos aqueles que ministrassem poções abortivas e filtros amorosos e aqueles que praticassem sacrifícios humanos, sendo que sob estes últimos recaía a pena de morte (SILVA, 2003, p. 230-231). Com a promulgação das Sentenças de Paulo temos também pela primeira vez o aparecimento nas leis do termo magia referindo-se às práticas de caráter mágico, então chamadas de carmina (encantamentos) e o termo magi, referindo-se aos magos, praticantes de magia. Por isso 
talvez Filóstrato tenha também tido ressalvas ao aproximar Apolônio dos sábios magos persas, como mostramos.

Em toda obra é destacada por Filóstrato a ligação de Apolônio com a filosofia pitagórica que, assim como o chamado médio-platonismo de Apuleio, admitiam as práticas teurgicas em larga escala. Segundo Jaap-Jan Flinterman (2009, p. 170), as características pitagóricas na $V A$ também podiam ser consideradas na época como características da magia nefasta, mas Filóstrato as alude em tom de comunicação de Apolônio com o divino. Todas as capacidades miraculosas de Apolônio são justificadas por sua filosofia pitagórica que lhe conduzia a uma rigorosa dieta e um estilo de vida capazes de lhe fazer ter presságios e ter poderes sobrehumanos.

O caráter divino de Apolônio também aparece na $V A$, quando Filóstrato ressalta seu biografado com tal característica por ser um sábio superior aos demais, sendo este elemento expresso pelo próprio autor/narrador ou pelas falas de personagens da obra. ${ }^{8}$

Por conseguinte, parece-me que não devo ver com indiferença a ignorância das pessoas, mas dar uma visão exata desse homem nos momentos nos quais falou ou fez cada coisa e as particularidades de sua sabedoria pelas quais foi considerado sobrenatural e divino (VA, I, 2). ${ }^{9}$

- Ele é, respondeu, divino Apolônio $(V A, \mathrm{I}, 21) \cdot{ }^{10}$

Também escreveu a seu rei, para que não fosse inferior a Vardanes a respeito de um homem grego e divino (VA, II, 17).1

[...] ainda que seja o mais divino entre os homens $(V A, \mathrm{II}, 29){ }^{12}$

Além disso, mandarei uma carta a Iarcas, o mais velho dos sábios, para que não acolha Apolônio como a alguém inferior a ele mesmo e a vós, como a filósofos e acompanhantes de um homem divino (VA, II, 41). ${ }^{13}$

- Eu penso, respondeu, que és o mais sábio e muito mais divino. (VA, III, $16)^{14}$

8 Citamos aqui apenas passagens nas quais Apolônio é mencionado como homem divino, mas há diversas passagens da $V A$ que características de um homem divino ficam evidentes.

9 Narrador.

10 Fala do sátrapa do reino parto.

11 Refere-se ao sátrapa indiano.

12 Fala de Fraotes, rei indiano.

13 Fala de Fraotes, rei indiano.

14 Fala de Iarcas, sábio indiano. 
[...] e há aqueles que jogaram pedras em cima dele e o injuriaram terrivelmente, a um homem divino e bom (VA, III, 25).

- Proponho-te um brinde, rei, por um homem grego, indicando Apolônio, que estava reclinado abaixo dele e denotando com um gesto de sua mão que era nobre e divino $(V A, \mathrm{III}, 28){ }^{15}$

Que conhecia de antemão essas coisas por impulso divino e que não eram corretos os que consideravam nosso homem um feiticeiro [...] (VA, $\mathrm{V}, 12)$.

Então dei-me conta pela primeira vez de que era divino e superior à sabedoria comum e corrente [...] (VA, VIII, 13). ${ }^{16}$

- Ouvi falar de ti, Apolônio, que és sábio em assuntos divinos (VA, VIII, 23). ${ }^{17}$

Não são claras as razões que levaram Filóstrato a desenvolver essa apologia de Apolônio ligando sua imagem relacionada à magia enquanto teurgia, distinta de outra tradição sobre o biografado. O biógrafo nos conta que escreveu a obra a pedido da imperatriz severiana Júlia Domna (VA, I, 3), esposa de Septímio Severo (193-211), o que pode ser real ou não, mas que de fato legitimava a escrita do texto. Jamais poderemos ter certeza se tal informação é verdadeira. A historiadora Maria Dzielska (1986, p. 188) acredita que sim, pois a imperatriz seria a única pessoa capaz de atrair a atenção de Filóstrato para Apolônio, um sábio de poderes mágicos, conhecido somente nas distantes regiões orientais do Império, de onde vinha também Júlia Domna, natural de Emesa, na Síria.

Também não sabemos da repercussão que a obra teve especificamente no contexto em que Filóstrato viveu, mas possivelmente ela foi lida pelos imperadores da época, já que além de Júlia se interessar pela obra, como conta Filóstrato, seu filho e imperador Caracala tinha interesses pelo tianeu como já mostramos na documentação e Severo Alexandre (222-235), o último imperador da dinastia dos Severos, parece ter rendido admiração especial por Apolônio, como mostra a História Augusta (Vida de Severo Alexandre, 29, 2). Chamar a atenção imperial para seus escritos através da apologia a um personagem por eles admirado pode ter sido um dos objetivos de Filóstrato com a escrita da $V A$.

15 Fala de Iarcas, sábio indiano.

16 Fala de Damis, discípulo de Apolônio e seu fiel seguidor que Filóstrato conta $(V A, \mathrm{I}, 3)$ ter escrito um diário sobre as viagens de Apolônio, sua principal fonte para escrita da $V A$.

17 Fala do governador da Grécia. O texto em grego trata este personagem como governador da Grécia, porém não existia uma Província da Grécia no Império Romano, acreditamos que talvez seja o governador da Província de Acaia. 
Para nós, a apologética biografia de Filóstrato pode ser pensada dentro dos próprios anseios do autor, que serviu a corte severiana e, para nós, legitima várias práticas destes imperadores na biografia do tianeu, como por exemplo, com relação ao culto ao Sol que os Severos foram adeptos e que Apolônio é apresentado como sacerdote em diversas passagens da VA. Sendo ainda os Severos, possivelmente admiradores de Apolônio, Filóstrato como um membro do grupo que servia à Corte, não seguiria uma memória negativa em torno de Apolônio, mas reconstrói a mesma dentro da própria ambiguidade que a magia apresentava no período, defendendo seu protagonista como um legítimo homem divino praticante da teurgia.

Filóstrato ainda aproveita a biografia sobre o tianeu para nos apresentar, de forma consciente ou não, várias outras de suas percepções políticas sobre o momento em que vivia e, em especial, destaca e afirma papeis para os sofistas gregos, grupo que fazia parte, na política e na administração do Império Romano no contexto severiano, tema que desenvolvemos em nossa tese de doutorado.

\section{Apolônio de Tiana na tradição da Antiguidade Tardia}

Autores posteriores a Filóstrato também fizeram referências a Apolônio. Dzielska (1986, p. 75) observa que Apolônio é citado como yóns - goes em uma homilia de João Crisóstomo. Apolônio é mencionado como magus pelo autor anônimo do século IV conhecido pela tradição como Peregrino de Bourdeaux..$^{18} \mathrm{E}$ suas práticas são ligadas a goeteia por Cirilo de Alexandria em breve menção no discurso Contra Juliano. ${ }^{19}$ Portanto, para esses autores da Antiguidade Tardia, o tianeu é revisitado sob julgamentos cristãos, como sendo um praticante de magia, um charlatão. Todavia, um testemunho particularmente interessante do período advém de Eusébio de Cesareia em Resposta a Hiérocles.

No texto Resposta a Hiérocles, o bispo cristão Eusébio critica Hiérocles, governador da Bitínia e perseguidor de cristãos ao lado do imperador Diocleciano (284-305), por ter comparado Apolônio de Tiana a Jesus Cristo, em uma obra chamada Amante da Verdade, desconhecida atualmente. Assim, temos apenas o testemunho de Eusébio que acusa Hiérocles de ter criado em Apolônio um rival para Jesus Cristo.

18 Informação contida no Corpus Christianorum Series Latina, 175, 10; CSEL, 39,16 - Peregrino de Boudeaux (333), sobre tal informação ver o catálogo realizado por Jones, nomeado como Testimonia (2006).

19 Além do material trabalhado neste texto, temos ainda citações sobre Apolônio no léxico bizântino Suda, na História Augusta e nos escritos de autores tardo-antigos como: Porfírio, Jâmblico, Arnóbio, Lactâncio, Libânio, Temístio, Jerônimo, Agostinho, Flávio Marcelino, Pseudo-Ambrósio, Eunápio, Sinésio, Nilo, Cirilo, Isidoro, Pseudo-Nono, Basílio, Macário e Sidônio Apolinário. 
A partir disso, alguns estudiosos desenvolveram trabalhos percebendo semelhanças quanto aos milagres realizados pelo Apolônio de Filóstrato e o Jesus dos Evangelhos (CORNELLI, 2001; PADILLA, 1991). Outros estudiosos ainda leram o Apolônio de Filóstrato como uma espécie de cristão, assim como Jesus foi lido como um homem divino ( $\theta \varepsilon \tilde{o}$ s àví $\rho$ theios aner), tal como o tianeu. Foram desenvolvidos diferentes estudos relacionando Apolônio e Jesus Cristo, desde especulações mais antigas, como a de Eduard Norden (1923 apud UYTFANGHE, 2009) e Alice Winston (1954), até textos mais recentes como os de Jacques Boulogne (1999), Cornelli (2001) e Marc Van Uytfanghe (2009).

Discordamos das propostas em ler o Apolônio filostratiano dentro da ótica do cristianismo, pois em Filóstrato, o tianeu não tem nenhum eco de cunho cristão. $O$ Apolônio de Filóstrato pode ter semelhanças com Jesus em relação aos poderes miraculosos, o que não discordamos. Entretanto, a relação do Apolônio de Filóstrato com o cristianismo é fruto de comparações dos personagens em meio às contendas da Antiguidade Tardia, que não estavam presentes em Filóstrato. Dessa maneira, ressaltamos, o Apolônio filostratiano possui elementos do contexto em que Filóstrato escreveu, mostrando anseios e escolhas do biógrafo sobre o que retratar de Apolônio.

Como vemos, na Antiguidade Tardia Eusébio criticou duramente Hiérocles e mostrou Apolônio como incapaz de ser divino e de fazer milagres por inspiração divina, o que estava reservado somente a Jesus na ótica do bispo de Cesareia. Eusébio considera o saber de Apolônio, mas apenas em nível humano. $O$ interessante é que Eusébio não critica a obra de Filóstrato, ao contrário, elogia o biógrafo como um erudito (EUSÉBIO DE CESAREIA, Resposta a Hiérocles, II). O problema, portanto, ocorria, para Eusébio, por conta da comparação feita de Apolônio com Cristo na obra de Hiérocles. Destacamos alguns trechos da obra do bispo cristão em que ele ataca Hiérocles e seu Apolônio comparado ao Salvador dos cristãos:

Não preciso dizer com qual admiração ele [referindo-se a Hiérocles], atribui os feitos taumatúrgicos não aos truques da feitiçaria, mas ao divino e ao conhecimento misterioso, tirando-o de culpa e o deificando, embora ele não apresente nenhuma prova disso (EUSÉBIO DE CESAREIA, Resposta a Hiérocles, II).

Para uma melhor análise do caso de Apolônio, ou mesmo para se questionar sobre os absurdos ditos sobre ele, vamos apenas analisar o trabalho de Filóstrato e, por um exame minucioso do mesmo, ver que Apolônio não estava apto a ser classificado entre os filósofos, mas sim, entre os homens de integridade e bom senso e, menos ainda, estava apto a ser comparado ao nosso Salvador Cristo, como podemos ver. 
Embora, de acordo com o Amante da Verdade, ele fosse muito educado, não era a acepção da verdade. Para tal temos a obra de Filóstrato, o ateniense, entre outras. Desta forma, nós devemos apreciar o valor da autoridade de acordo com ele. Eles [referindo-se aos outros testemunhos sobre Apolônio, como Filóstrato] eram altamente educados, ainda que nunca tenham refletido com cuidado sobre o caso de Apolônio em fatos. Quando nós examinamos estes fatos, não temos dúvidas das claras demonstrações de solidez e, como as imagens dele mesmo, da precisão no detalhe da condenação que merece a obra Amante da Verdade, que tem sido posse de todos os supremos tribunais das províncias, pesando sob os cristãos, o que eles clamam como falsa credulidade, considerada como tolice de mortais iludidos (EUSÉBIO DE CESAREIA, Resposta a Hiérocles, IV).

Assim, embora não tenhamos o testemunho de Hiérocles em si, podemos ver nesta contenda entre Eusébio e Hiérocles o surgimento, em meio às perseguições aos cristãos empreendidas por Diocleciano, de uma possível tentativa de criação, por parte de Hiérocles, de um "pagão" superior a Cristo e seu possível "rival". Já em Eusébio, temos a tentativa do bispo cristão de desqualificar o suposto rival de seu senhor e salvador, o único ser divino para ele.

\section{Apolônio de Tiana em algumas representações contemporâneas}

Como comentamos na introdução deste artigo, ainda hoje a imagem de Apolônio causa inquietação, despertando a atenção não apenas dos estudos acadêmicos que buscam pelo Apolônio histórico e pelas variadas representações que dele foram feitas, mas também de correntes místicas como a Teosofia que, como observa Cornelli (2001, p. 69), se remete aos mistérios antigos e considera Apolônio como um iniciado. Tal constatação pode ser vista por nós na internet em diversos sites, como o intitulado Estudo Teosófico, que traz uma matéria comparando Buda, Apolônio de Tiana e Jesus Cristo em matéria não assinada, publicada em 2012. Segundo a matéria:

Como Buddha e Jesus, Apolônio foi um intransigente inimigo de toda a ostentação exterior de piedade, de toda a exibição de cerimônias 
religiosas inúteis e de toda a hipocrisia. Se, como o Salvador cristão, o sábio cristão, o sábio de Tyana tivesse, por preferência, buscado a companhia do pobre e do humilde; e se, ao invés de morrer confortavelmente, e com mais de cem anos de idade, tivesse sido um mártir voluntário, proclamado a verdade divina de uma cruz, seu sangue se teria provado tão eficaz para a subsequente disseminação das doutrinas espirituais, como o do Messias cristão [...] Se estudarmos o assunto com um espírito imparcial, percebemos rapidamente que as éticas de Gautama Buddha, Platão, Apolônio, Jesus, Amônio Saccas, e seus discípulos, baseavam-se todas na mesma filosofia mística; que todos reverenciavam um Deus, seja O considerado como o "Pai" da Humanidade, que vive no homem como o homem vive nele, seja como o Incompreensível Princípio Criador; todos viveram vidas sublimes [...] (ESTUDO TEOSÓFICO, 2012).

Parece-nos que em sites esotéricos a memória que prevaleceu em torno de Apolônio foi aquela construída por Filóstrato em sua longa tentativa de salvar seu personagem da imagem de goes, o feiticeiro charlatão, ou aquela dos escritores que o compararam a Jesus Cristo. As especulações não acadêmicas, neste sentido, também são muitas pelos sites de cunho místico e religioso.

Da mesma forma, George Mead, estudioso de Teosofia do final do século XIX e início do século XX, dedicou uma obra de cunho esotérico para estudar a vida do tianeu através da biografia de Filóstrato. A obra de Mead sobre Apolônio de Tiana data de 1901, embora encontremos edições da mesma até os dias atuais, lançadas por editoras de cunho esotérico. Mead (2013) defende que Apolônio de Tiana foi um profeta reformador e que não foi considerado como um grande iniciado da Antiguidade pela literatura religiosa contemporânea por não estar relacionado aos feitos judaico-cristãos.

Não queremos aqui entrar no debate sobre a comparação de características miraculosas entre Apolônio e Jesus, o que tem sido amplamente estudado por vários estudiosos como já comentamos. Mas não podemos, entretanto, deixar de mencionar que o tianeu também foi tema do Episódio 2, Rivals of Jesus, parte do documentário Secret Bible, produzido pelo canal National Geographic. Neste documentário, Apolônio é mostrado, de forma bastante sensacionalista, como um dos rivais de Cristo. No vídeo, os rivais de Cristo são considerados homens que propagavam outras religiões dentro do Império Romano, o que não nos parece correto para o tianeu, pois nosso protagonista é apresentado em toda documentação 
cultuando os deuses greco-romanos, em especial a divindade solar Hélio, na $V A$ de Filóstrato. $^{20}$

Apolônio no documentário da National Geographic é um homem da "paz e do amor", nas próprias palavras do narrador do vídeo. Apolônio cura ferimentos, ressuscita, ensina, alimenta e faz milagres aos pobres em regiões do Império Romano, uma imagem que tenta aproximá-lo ainda mais de Jesus dos Evangelhos, como seu maior rival, e que se aproxima do que estaria em Filóstrato quanto aos milagres e ao curandeirismo. Porém, essa imagem se distancia bastante do conselheiro imperial romano, do filósofo dos grupos das elites atuante na administração romana, bem característica do Apolônio da VA. Talvez essa comparação advenha da contenda apresentada por Eusébio em sua Resposta a Hiérocles que, por sua vez, escreveu a obra em que compara Apolônio com Jesus em meio aos problemas que lhe eram contemporâneos, como comentamos.

Ao que nos parece, no percurso da fortuna da memória de Apolônio como feiticeiro charlatão e homem divino no Principado Romano e rival de Cristo na Antiguidade Tardia, da Antiguidade à Contemporaneidade, acabou prevalecendo aspectos que o relacionam com a imagem e com as curiosidades em torno da vida de Jesus e das especulações pouco dotadas de teor acadêmico. Tais especulações, por sua vez, são bastante sensacionalistas sobre o caráter do Jesus histórico, como vemos no trecho abaixo, tirado do site do canal National Geographic (2017):

\begin{abstract}
Ele curou os doentes, alimentou os famintos e ressuscitou os mortos. Ele fez milagres e seus seguidores disseram que era o Filho de Deus. Três dias depois de sua morte, ressuscitou para proclamar a salvação ao mundo. Seu nome... Apolônio de Tiana. E ele foi apenas um dos vários pregadores e milagreiros do século I que rivalizaram com a fama e o seguimento de Jesus. Quem eram esses Rivais de Cristo? Por que o mundo mediterrânico do século I d.C. parece ter criado tantos Messias? E por que a fé de Jesus venceu as seitas semelhantes da época?21
\end{abstract}

Assim, as memórias em torno de Apolônio continuam sendo revisitadas, muitas vezes sem a preocupação com uma análise histórica da documentação que chegou até nós, mas de acordo com os interesses contemporâneos de quem divulga estas memórias. E um dos

20 Sobre a aproximação de Apolônio de Tiana a uma divindade de atributos solares na VA, no caso o deus grego Hélio, lemos a mesma como uma das tentativas de Filóstrato em aproximar o tianeu de elementos da dinastia severiana, governante na época de elaboração da obra e seguidores de uma divindade também de atributos solares da região síria de onde vinham.

21 Comentário do Episódio 2 do Documentário Secret Bible. 
interesses principais, pelo que vemos, é compreender mais sobre Jesus e seu contexto, ainda que muitos esforços careçam de embasamento histórico e crítica documental.

\section{Considerações Finais}

Diante do que foi apresentado, vimos que a imagem de Apolônio variou no período do Principado romano de maneira totalmente oposta e que os autores que o consideravam um feiticeiro charlatão seguiam as concepções dos grupos de elites sobre as práticas mágicas de goeteia, punidas pelas leis da República e do Principado. Dessa forma, foi na Antiguidade Tardia, nas lutas de representações cristãs e "pagãs" daquele contexto, que surgiram as comparações de Apolônio com Cristo, ausentes da documentação do Principado. Tais comparações configurarão uma imagem de Apolônio que o ligará a Jesus Cristo nas memórias preservadas atualmente sobre o tianeu.

Portanto, as imagens de Apolônio e as representações que foram sendo construídas sobre o personagem na Antiguidade variaram de autor para autor conforme as necessidades e objetivos de cada um, mas dentro de lógicas e padrões culturais reconhecidos por seus contemporâneos, construindo memórias e lembranças sobre o personagem.

Assim, a memória sobre Apolônio que permanece mais comumente na atualidade nos leva a percebê-lo como um personagem que, apesar de tão longínquo no tempo e no espaço, ainda é capaz de suscitar interesses e inquietações contemporâneos. Em geral, muitos desses interesses atuais sobre o tianeu estão voltados para entender o Jesus histórico. Podemos ver que, outras vezes, há interesses em ver Apolônio como um modelo de místico e de homem religioso iniciado, memória essa presente em meio às buscas de grupos esotéricos e místicos.

Por fim, cumpre ressaltar que no Brasil, um país onde temos a forte presença de religiosidades mágicas consideradas muitas vezes de maneira preconceituosa e também ambígua, como é o caso da umbanda e do candomblé, pensar a magia romana e personagens significativos como Apolônio, é uma oportunidade para refletirmos sobre aspectos de nossas próprias crenças e de nossas ideias religiosas preconcebidas. Tudo isso nos leva a pensar sobre as imagens da religiosidade e sobre alguns personagens antigos criados e recriados como representações e como memórias selecionadas. Neste sentido, tais memórias cumprem o papel de verdadeiros mecanismos necessários para transmitir e defender concepções de mundo e valores de grupos. 


\section{Referências}

APOLLONIUS OF TYANA. Letters of Apollonius. In: PHILOSTRATUS. The Life of Apollonius of Tyana. Tradução de Christopher P. Jones. Cambridge: Harvard University Press, 2006. v. III.

APULEYO. Apologia. Tradução de Santiago Segura Munguía. Madrid: Editorial Gredos, 1980.

APULEYO. El asno de ouro. Madrid: Alianza Editorial, 1988.

BOULOGNE, Jacques. Apollonios de Tyane. Le mythe avorté d'une sagesse totale, Bulletin de L'Association Guillaume Budé, octobre, 1999, p. 300-310.

BRANDÃO, Jacyntho Lins. A adivinhação no mundo helenizado do II século. Clássica, São Paulo, n. 4, p. 103-121, 1991.

CASSIUS DIO. Dio's Roman History. Tradução de Earnest Cony. London: Harvard William Heinemann; Harvard University Press, [1923?]

CORNELLI, Gabriele. Sábios, Filósofos, Profetas ou Magos? Equivocidade na recepção das figuras de $\theta \varepsilon i ̃ o$ ö $\nu \rho \rho \varepsilon \varsigma$ na literatura helenística: a magia incômoda de Apolônio de Tiana e Jesus de Nazaré. 2001. Tese (Doutorado em Ciências da Religião) - Universidade Metodista de São Paulo, São Paulo, 2001.

DODDS, Eric Robertson. Teurgia. In: Os gregos e o irracional. São Paulo: Escuta, 2002. p. 284-314.

DZIELSKA, Maria. Apollonius of Tyana in legend and history. Problemi e ricerche di Storia Ântica. Roma: L'Erma di Bretschneider, 1986.

ESTUDO TEOSÓFICO. Considerações sobre Buddha, Jesus e Apolônio de Tiana. 2012. Disponível em: <http://www.teosofico.com/livros/h-p-blavatsky/isis-semv\%C3\%A9u/considera\%C3\%A7\%C3\%B5es-sobre-buddha-jesus-e-apol\%C3\%B4nio-detiana>. Acesso em: 6 jun. 2016.

EUSEBIUS. Reply to Hierocles. In: PHILOSTRATUS. The Life of Apollonius of Tyana. Tradução de Christopher P. Jones. Cambridge: Harvard University Press, 2006. v. III, p. 145-257. 
FILÓSTRATO. Vida de Apolônio de Tiana. Tradução de Alberto Bernabé Pajares. Madrid: Editorial Gredos, 1979.

FLINTERMAN, Jaap-Jan. The ancestor of my wisdom: Pytagoras and Pythagoreanism in Life of Apollonius. In: BOWIE. E.; ELSNER, J. Philostratus. Cambridge: Cambridge University Press, 2009.

JONES, Christopher (Ed.). Testimonia. In: Philostratus. Apollonius of Tyana. Cambridge: Harvard University Press, 2006, p. 81-143.

LE GOFF, Jacques. História e memória. Tradução de Bernardo Leitão. Campinas: Editora da UNICAMP, 1990.

LUCIANO. Alejandro o el falso profeta. In: _ _ _ _. Obras. Tradução de José Luís Navarro Gonzales. Madrid: Gredos, 1988. v. II.

MEAD, George Robert Stowe. Apolónio de Tiana. Taumaturgo contemporâneo de Jesus. Alto do Quintão: Apeiron Edições, 2013.

NATIONAL GEOGRAPHIC. Os segredos da Bíblia. Episódio 2: Os rivais de Jesus. Disponível em: <http://www.dailymotion.com/video/x1t3134_segredos-da-biblia-osrivais-de-jesus-natgeo_shortfilms>. Acesso em: 15 jun. 2017.

PADILLA, Carmen. Los milagros de la Vida de Apolonio de Tiana: morfologia del relato de milagro y generos afines. Estudios de Filologia Neotestamentaria 4. Cordoba: El Almendro, 1991.

PAJARES, Alberto Bernabé. Traducción, introducción y notas. In: FILÓSTRATO. Vida de Apolônio de Tiana. Madrid: Editorial Gredos, 1979, p. 7-57.

PENELLA, Robert. Philostratus'Letters to Julia Domna. Hermes, v. 107, n. 2, 1979, p. 161-168.

PHILOSTRATUS. The Life of Apollonius of Tyana. Tradução de Cristopher P. Jones. Cambridge: Harvard University Press, 2005. v. I, II.

RENBERG, Gil. Magic in the Daily Life of a Roman Province: The North African Background of Apuleius's Trial for Sorcery. School of Arts and Sciences. Disponível em: $<$ http://ccat.sas.upenn.edu/jod/apuleius/>. Acesso em: 03 jan. 2006.

RIVES, James. Magic in Roman Law: the reconstruction of a crime. Classical Antiquity, Berkeley, v. 22, n. 2, p. 313-339, 2003. 
SCRIPTORES. Severus Alexander. In: The Historia Augusta. Tradução de David Magie. Disponível em: <http://penelope.uchicago.edu/Thayer/E/Roman/Texts/ Historia_Augusta/home.html>. Acesso em: 4 mar. 2013.

SILVA, Gilvan. Ventura da. Reis, Santos e Feiticeiros: Constâncio II e os fundamentos místicos da Basiléia. (337 - 361). Vitória: EDUFES, 2003.

UYTFANGHE, Marc Van. La Vie d'Apollonius de Tyane et le discours hagiographique. In: DEMOEN, Kristoffel; PRAET, Danny. (Ed.). Theios Sophistes. Essays on Flavius Philostratus' Vita Apollonii. Leiden/Boston: Brill, 2009, p. 335-374.

YSSELT, Dorine van Sasse van. Stradanus drawings for the "Life of Apollonius of Tyana", Master Drawings, New York, v. 32, n. 4, 1994, p. 351-359.

WINSTON, Alice. Apollonius of Tyana, founder of Christianity. New York: Vantage Press, 1954.

Recebido em 05/09/2017

Aprovado em 06/06/2018 